\title{
História e memória da EJA nas universidades brasileiras e portuguesas - séculos XX e XXI
}

\author{
History and memory of EJA in Brazilian and Portuguese \\ universities - Twentieth and Twenty-first centuries \\ Historia y memoria de EJA en universidades de Brasil y de \\ Portugal - siglos XX y XXI
}

\section{Organização}

Sônia Maria dos Santos

Universidade Federal de Uberlândia (Brasil)

https://orcid.org/0000-0002-7217-1576

http://lattes.cnpq.br/9281057859793276

soniaufu@gmail.com

Francisca Izabel Pereira Maciel

Universidade Federal de Minas Gerais (Brasil)

https://orcid.org/0000-0003-4751-2890

http://lattes.cnpq.br/0925119698225692

emaildafrancisca@gmail.com

\section{Apresentação}

A história da Educação de Jovens e Adultos (EJA) se consolidou como um campo de pesquisa que vem ganhando espaço na Academia, devido ao diálogo que faz com diferentes temáticas da historiografia. Esse campo, portanto, provoca práticas e reflexões que não estão inscritas, especificamente, no âmbito escolar, pois vão muito além. É uma história contada a partir das relações de gênero, do trabalho, da política, do corpo, entre muitas outras perspectivas que revelam facetas múltiplas de um mesmo objeto. Entretanto, embora reconheçamos que exista um aumento vertiginoso das pesquisas sobre a História da EJA nos últimos 20 anos, ainda há uma tímida produção, se a compararmos, por exemplo, com a história da educação primária. Dessa maneira, este Dossiê tem por objetivo promover um diálogo entre pesquisadores sobre a história da educação de jovens e adultos em universidades brasileiras e portuguesas, nos séculos XX e XXI. 
O dossiê é composto de seis artigos; três deles foram escritos por pesquisadores brasileiros e portugueses, e nessa coautoria analisam duas realidades tão distantes e ao mesmo tempo com muitas proximidades. Nos outros três artigos, os autores, pesquisadores brasileiros, abordam, especificamente, a realidade da EJA no Brasil.

Este dossiê traz olhares que se aproximam sobre as relações entre as universidades e a EJA, a partir da década de 70 do século XX à atualidade. É uma história do tempo presente que precisa ser contada, pois os dados atualizados apontam que a taxa de analfabetismo da população com 15 anos ou mais de idade no Brasil caiu de 7,2\% em 2016 para 7,0\% em 2017, mas não alcançou o índice de 6,5\% estipulado, ainda para 2015, pelo Plano Nacional de Educação (PNE). A realidade brasileira aponta-nos que temos cerca de 11,5 milhões de pessoas com 15 anos ou mais que não sabem ler e escrever, e apenas 118 mil analfabetos frequentaram cursos de alfabetização no ano de $2017^{1}$. Partindo desses dados, é mais triste saber que a maioria dos analfabetos brasileiros continuam fora do espaço escolar e privados de seus direitos. Não incluímos, nesse somatório, os dados da pesquisa Indicador de Alfabetismo Funcional (INAF) em 2018, que elevaria ainda mais esse percentual, uma vez que a pesquisa mede os níveis de alfabetismo ${ }^{2}$ da população brasileira com idade acima de 15 anos $^{3}$.

Diante desses dados alarmantes e, infelizmente, históricos na educação brasileira, este dossiê traz à tona os debates, os impasses, os lugares e não lugares da Educação de Jovens e Adultos, principalmente nos estudos e nas pesquisas sobre a alfabetização de jovens e adultos no contexto brasileiro e português. Ao mesmo tempo, os estudos aqui reunidos mostram o que temos feito, produzido e pesquisado para uma melhor compreensão desse fenômeno que impera no Brasil.

Abrimos o dossiê com o artigo de Rocha e Goulart, em que os autores buscam contemplar uma área pouco explorada, ou seja, a EJA nas pesquisas acadêmicas, com o enfoque na produção voltada especificamente sobre a alfabetização. O artigo objetivou analisar e compreender a história da alfabetização de jovens e adultos no Brasil, a partir dos discursos acadêmicos produzidos no período de 1978 a 2000. Os autores realizaram um levantamento bibliográfico de teses e dissertações publicizadas no país no decurso do século $\mathrm{XX}$, considerando como as pesquisas oriundas das universidades brasileiras abordaram o tema da alfabetização de jovens e adultos.

Ainda que, em termos quantitativos, essa produção não seja tão expressiva, foram identificadas 65 produções, e dentro da análise da categoria "temáticas priorizadas", destacaram-se: 'Programas, projetos, iniciativas governamentais e não governamentais', seguidos de "Vivências de alfabetização de jovens e adultos" e 'Representações sobre a alfabetização de jovens e adultos'. Essa análise dos autores dialoga com os artigos subsequentes deste dossiê.

O segundo e o terceiro artigo têm em comum o diálogo entre instituições e projetos de extensão em que articulam a pesquisa, a docência, a formação e a especialização de professores da EJA. Outra afinidade nos artigos de Maciel e Santos e o de Porcaro está nos diálogos entre três universidades mineiras: Universidade Federal de Uberlândia (UFU), de Minas Gerais (UFMG) e de Viçosa (UFV). Todas as autoras atuam como professoras formadoras e pesquisadoras da EJA, com destaque para o campo da alfabetização de jovens e adultos. As semelhanças estão nas

\footnotetext{
${ }^{1}$ Cf. Calçade, 2018.

${ }^{2}$ Definição do INAF para alfabetismo: "é a capacidade de compreender e utilizar a informação escrita e refletir sobre ela, um contínuo que abrange desde o simples reconhecimento de elementos da linguagem escrita e dos números até operações cognitivas mais complexas, que envolvem a integração de informações textuais e dessas com os conhecimentos e as visões de mundo." (AÇÃO EDUCATIVA; INSTITUTO PAULO MONTENEGRO, 2018, p. 4).

${ }^{3}$ Cf. Ação Educativa; Instituto Paulo Montenegro, 2018.
} 
atuações e coordenações de projetos de extensão voltados para o campo da EJA, nos embates que esses projetos encontram dentro da Academia e na perseverança das autoras em levar adiante projetos considerados longevos, quando o mais comum é a terminalidade após dois ou quatro anos de execução. Perseverança como uma opção política de acreditar que a alfabetização de jovens e adultos é um direito e, dessa forma, continuar defendendo os princípios freireanos de propiciar um aprendizado que faça sentido na vida das pessoas.

Insta destacar que esses três artigos buscam evidenciar a articulação entre a extensão, a pesquisa e a especificidade da formação do educador da EJA na universidade. Essa articulação, problematizada nos textos das autoras, tem sido um dos objetivos perseguidos pelas pesquisadoras nas suas trajetórias acadêmicas e, em parte, com retorno bem sucedido ao longo de três décadas. A formação do professor alfabetizador de EJA e a especificidade necessária a essa formação, ainda pouco valorizada também nas pesquisas acadêmicas, como aponta o artigo de Rocha e Goulart, tem sido uma defesa para a continuidade desses projetos de extensão.

Neste dossiê, são, ainda, tematizadas e discutidas as políticas públicas, as histórias de vida e identidade da EJA sob o ponto de vista de pesquisadores de dois países: Brasil e Portugal. No primeiro deles, Oliveira e Amaral partem da legislação portuguesa e brasileira para analisar a história das políticas de democratização da Educação de Adultos nos dois países, história essa analisada sob o ponto de vista da inserção desse público no ensino superior. Atualmente, de acordo com os estudos e as investigações no campo da EJA, torna-se imprescindível inserir o segmento da EJA no Ensino Superior, não só por ser o aluno um trabalhador, e sim pelas suas histórias marcadas por rupturas e descontinuidades no processo de escolarização. Oliveira e Amaral também rememoram as histórias de vidas desses alunos e trazem pontos comuns entre os dois países. A distância geográfica entre Brasil e Portugal torna-se inexpressiva com as semelhanças entre os alunos da EJA de lá e de cá do Atlântico.

As autoras Vieira, Moio e Lima também trazem suas reflexões a respeito da entrada tardia dos alunos de EJA no ensino superior. Sob o título Histórias de ingresso de jovens maiores de 23 anos no ensino superior em Portugal, as autoras apresentam a história da educação de adultos em Portugal, do século XVI à educação de jovens e adultos durante e após a Revolução de 1974. Na sequência, as autoras refletem sobre a inserção dos adultos no ensino superior, tema que já vem sendo debatido no meio acadêmico português. Diferentemente do que ocorre entre nós, brasileiros, esse é um tema ainda pouco explorado, ou mais adequado dizer, não enfrentado por nós, pesquisadores e acadêmicos.

São muitas as perguntas que carecem de respostas e pesquisas. Esses alunos oriundos da EJA, quem são eles? Quais os cursos escolhidos por eles? Ou serão os cursos que escolhem seus alunos? Essas são temáticas que ainda precisam ser investigadas. O acesso democrático desse público à universidade tem garantido a esses alunos o desejo de cursar o que realmente querem? Esses artigos nos incitam a entrar nessa vereda.

No último artigo do dossiê, de autoria de Machado e Barros, cujo título é Aspectos da construção histórica da identidade da EJA no Brasil e em Portugal: enfoque na agenda política e suas práticas discursivas, as autoras tematizam os três campos da EJA: o campo das práticas educativas, o das práticas de investigação e o das práticas discursivas, priorizando a análise deste último. Apresentam-nos a história da EJA em Portugal e no Brasil, a partir da análise da legislação, focalizando nas práticas discursivas inerentes à agenda política. Analisam, a partir dos discursos legais, o processo de democratização da EJA nos dois países, apontando as semelhanças e as diferenças.

Há que ressaltar que esses artigos foram produzidos em um contexto brasileiro diferente do que estamos vivenciando hoje, após a posse do presidente Jair Bolsonaro. Foram produzidos antes da extinção da Secadi (Secretaria de Educação Continuada, Alfabetização, Diversidade e Inclusão), secretaria responsável pelas ações da EJA. E no dia 11 de abril de 
2019, foi lançado, em um documento de 56 páginas, a "Política Nacional de Alfabetização (PNA)", instituída pelo Decreto $\mathrm{n}^{\circ}$ 9.765. Nesse documento, a parte que diz especificamente sobre a alfabetização de jovens e adultos fica restrita a seis parágrafos.

Portanto, os artigos deste dossiê refletem uma análise em que apontamos os desafios, ao lado dos avanços, da longevidade dos projetos de extensão, da articulação entre ensino, pesquisa e extensão e, mais do que isso, da esperança que nos leva a acreditar que a história da Educação de Jovens e Adultos não pode ter um retrocesso, tal como vivenciado em 1964 e, posteriormente, com o fracasso do Mobral.

Aos leitores, este dossiê é um convite para pensarmos e analisarmos a história da Educação de Jovens e Adultos, em interface com a história da Universidade - do ensino, da extensão e da pesquisa -, e sabermos onde poderemos fazer a diferença frente aos próximos anos. Continuemos firmes com Paulo Freire, acreditando que precisamos esperançar. Façamos desse verbo o nosso lema para a EJA.

\section{Referências}

AÇÃO EDUCATIVA; INSTITUTO PAULO MONTENEGRO. Indicador de Alfabetismo Funcional (Inaf) Brasil 2018: resultados preliminares. São Paulo: Ação Educativa; IPM, 2018. Disponível em: <http://acaoeducativa.org.br/wpcontent/uploads/2018/08/Inaf2018_Relat\%C3\%B3rio-Resultados-Preliminares_v08A go2018.pdf>. Acesso em: 19 abr. 2019. https://doi.org/10.31368/1980-6221r00382018

CALÇADE, Paula. As taxas de analfabetismo ainda são altas no Brasil? 2018. Disponível em: <https://novaescola.org.br/conteudo/12398/as-taxas-de-analfabetismo-ainda-sao-altas-no brasil>. Acesso em: 20 abr. 2019. https://doi.org/10.17771/pucrio.acad.11041 